\title{
Reactive Oxygen Species-Mediated Loss of Synaptic Akt1 Signaling Leads to Deficient Activity-Dependent Protein Translation Early in Alzheimer's Disease
}

\author{
Faraz Ahmad,, Kunal Singh,, Debajyoti Das, Ruturaj Gowaikar, Eisha Shaw, Arathy Ramachandran, \\ Khader Valli Rupanagudi, Reddy Peera Kommaddi, David A. Bennett, and Vijayalakshmi Ravindranath ${ }^{1,3}$
}

\begin{abstract}
Aims: Synaptic deficits are known to underlie the cognitive dysfunction seen in Alzheimer's disease (AD). Generation of reactive oxygen species (ROS) by $\beta$-amyloid has also been implicated in AD pathogenesis. However, it is unclear whether ROS contributes to synaptic dysfunction seen in AD pathogenesis and, therefore, we examined whether altered redox signaling could contribute to synaptic deficits in AD.

Results: Activity dependent but not basal translation was impaired in synaptoneurosomes from 1-month old presymptomatic $\mathrm{APP}^{\mathrm{Swe}} / \mathrm{PS} 1 \Delta \mathrm{E} 9$ (APP/PS1) mice, and this deficit was sustained till middle age (MA, 9-10 months). ROS generation leads to oxidative modification of Akt1 in the synapse and consequent reduction in Akt1-mechanistic target of rapamycin (mTOR) signaling, leading to deficiency in activity-dependent protein translation. Moreover, we found a similar loss of activity-dependent protein translation in synaptoneurosomes from postmortem AD brains.

Innovation: Loss of activity-dependent protein translation occurs presymptomatically early in the pathogenesis of AD. This is caused by ROS-mediated loss of pAkt1, leading to reduced synaptic Akt1-mTOR signaling and is rescued by overexpression of Akt1. ROS-mediated damage is restricted to the synaptosomes, indicating selectivity. Conclusions: We demonstrate that ROS-mediated oxidative modification of Akt1 contributes to synaptic dysfunction in $\mathrm{AD}$, seen as loss of activity-dependent protein translation that is essential for synaptic plasticity and maintenance. Therapeutic strategies promoting Akt1-mTOR signaling at synapses may provide novel target(s) for disease-modifying therapy in AD. Antioxid. Redox Signal. 27, 1269-1280.
\end{abstract}

Keywords: translation, oxidation, Alzheimer's

\section{Introduction}

A LZHEIMER'S DISEASE (AD) is one of the most devastating disorders seen in aged people. As life span increases across the world, the number of people afflicted by AD and other dementias is set to increase globally. There are no cures or disease-modifying therapies that can delay the onset and/ or slow down the progression of AD. Structural MRI and PET imaging of $\beta$-amyloid in human subjects have revealed that accumulation of $\beta$-amyloid, thinning of cortex, and decrease in hippocampal volume occur in the prodromal stage of the disease, years or decades before onset of cognitive dysfunction (20). Thus, it is important to identify the subcellular targets and molecular substrates of the degenerative processes that occur early in the disease process, before onset of cognitive impairment in AD, to identify biomarkers and develop drug targets for disease-modifying therapies.

Oxidative stress and synaptic dysfunction are considered to be among the primary events in $\operatorname{AD}$ pathogenesis $(7,31)$. Structural changes seen as loss of synapses correlate with

\footnotetext{
${ }^{1}$ Centre for Neuroscience, Indian Institute of Science, Bangalore, India.

${ }^{2}$ Rush Alzheimer's Disease Center, Rush University Medical Center, Chicago, Illinois.

${ }^{3}$ Centre for Brain Research, Bangalore, India.
}

(C) Faraz Ahmad et al., 2017; Published by Mary Ann Liebert, Inc. This Open Access article is distributed under the terms of the Creative Commons Attribution Noncommercial License (http://creativecommons.org/licenses/by-nc/4.0/) which permits any noncommercial use, distribution, and reproduction in any medium, provided the original author(s) and the source are credited. 


\section{Innovation}

The major finding in this study is that protein translation at the level of postnuclear supernatant is unaltered in Alzheimer's disease (AD), but activity-driven protein translation at synapse is compromised from an early stage of disease progression. We also provide evidence for compromised synaptic Akt1-mechanistic target of rapamycin (mTOR) signaling cascade leading to this effect. Furthermore, we show that this deficit can be reversed by ectopic overexpression of Akt1, indicating a target for potential therapeutic intervention to retard the progression of AD. The major results from the study are outlined as follows:

(i) Loss of activity-dependent protein translation, critical for synaptic plasticity and maintenance, was observed in cortical synaptoneurosomes from APP/PS1 mice and postmortem AD brains.

(ii) This is caused by increased reactive oxygen species (ROS) generation in synaptosomes leading to redox modification of Akt1, resulting in compromised Akt1-mTOR signaling.

(iii) Although there is overall generation of ROS, synaptic phosphorylated Akt1 is specifically compromised because of redox modification.

(iv) Activity-dependent protein translation can be modulated by $\mathrm{A} \beta$-generated $\mathrm{ROS}$ through Akt1 thiol modification.

(v) ROS-mediated synaptic pathology in AD starts very early in life, whereas overt behavioral and pathological symptoms are evident much later.

cognitive dysfunction in human subjects and mice that carry human mutations of familial AD (35). However, the molecular underpinnings of synaptic deficits and the targets of reactive oxygen species (ROS)-mediated neurodegeneration are poorly understood.

Protein translation (basal and neuronal activity-dependent) occurring at the synapse is critical for synapse maintenance and plasticity $(10,36)$. Akt1-mammalian target of rapamycin (mTOR) signaling mediates cap-dependent protein translation, which accounts for most of the protein translation occurring in the cell (30). In particular, it is critical for activity-dependent local protein synthesis at the synapse in neurons (39). Akt (or PKB) is a cell survival kinase whose activity requires phosphorylation at $\mathrm{Thr} 308$ in the activation loop of the kinase domain and at Ser473 in the C-terminal hydrophobic domain (18). Phosphorylated Akt1 (pAkt1) indirectly activates mechanistic target of rapamycin (mTOR) by phosphorylating TSC1/2 complex, the inhibitory regulator of mTOR, thereby activating mTOR pathway that culminates in phosphorylation of 4EBP1 at Thr46/47 and S6K at Thr389, both important regulators of cap-dependent protein translation (34). Although S6K phosphorylates S6 ribosomal protein and induces protein translation, 4EBP1 is a translational repressor that binds to eukaryotic translation initiation factor $4 \mathrm{E}$ (eIF4E) and regulates binding of mRNA to small ribosomal subunit and phosphorylated (pmTOR)-mediated phosphorylation dissociates it from eIF4E, hence removing its inhibitory effects on translation initiation complex (13).

Interestingly, although dysregulation of Akt1 signaling has been observed in postmortem brain tissue from AD patients and in animal models of $\mathrm{AD}(9,16,23,26,27,33,34 \mathrm{a}, 37,38$, 46), two critical questions remain unanswered. On one hand, we do not have a clear understanding of the molecular mechanisms that lead to defective Akt1 signaling. On the other, the functional consequences of this deficit in the perspective of neurodegeneration are yet to be discerned. We now present evidence that defective Akt1 signaling is mediated by oxidative modification of Akt1, occurring presymptomatically as early as 1 month of age in the APP/PS1 transgenic mouse model of AD. The loss of Akt1 kinase occurs in the synaptic compartment and consequently affects activity-dependent protein translation, leading to potential synaptic dysfunction.

We analyzed local protein translation in synaptoneurosomes isolated from frontal cortical tissue samples of postmortem brains from persons with and without AD. Although basal protein translation was found to be unaffected, $\mathrm{KCl}$ stimulated protein translation was found to be defective in neocortical tissue samples from postmortem brains of $\mathrm{AD}$ patients. Furthermore, to determine the molecular mechanism responsible for this dysfunction, we used a mouse model of $\mathrm{AD}, \mathrm{APP}^{\mathrm{Swe}} / \mathrm{PS} 1 \Delta \mathrm{E} 9$ (APP/PS1) mice, and studied the Akt1mTOR signaling pathway that is a critical regulator of protein translation and homeostasis at the synapse $(15,19,28,36,44)$. Our studies were carried out in three ages of mice: adolescent (ADL) animals (1-1.5 months old), young adults (YA, 3-4 months old) before the onset of pathological hallmarks and memory dysfunction, and MA mice (9-12 months of old) when both these features of the disease are evident. In addition, using cultured primary cortical neurons from APP/PS1 mice, we sought to determine whether ectopic overexpression of a constitutively active Akt1 [myristoylated Akt1; (42)] could rescue the stimulated protein translation at the synapse.

\section{Results}

\section{Activity-dependent translation is repressed in synaptoneurosomes of APP/PS1 mice from a very young age}

We assessed basal and activity-dependent protein translation in synaptoneurosomal (Fig. 1A-C) and postnuclear supernatant (PNS) (Fig. 1E) fractions isolated from APP/PS1 mouse brain cortex at 1, 3, and 9-11 months of age. Upon stimulation of synaptoneurosomes isolated from cortex of wild type (WT) mice with $\mathrm{KCl}$, we observed increased $\mathrm{S}^{35}$ methionine incorporation as has been previously reported [Fig. 1F; (32)]. $\mathrm{S}^{35}$-methionine incorporation was absent in the presence of cycloheximide. Absence of radioactivity from the last methanol wash of the trichloroacetic acid (TCA) precipitate provided evidence for removal of all unbound $S^{35}$ methionine from the reaction mixture (Fig. 1F), indicating that the measured radioactivity from TCA pellets was contributed solely by $\mathrm{S}^{35}$-methionine incorporated into nascent proteins. Unlike the WT synaptoneurosomes, $\mathrm{KCl}$-stimulated protein translation was absent in synaptoneurosomes isolated from APP/PS1 mice at all ages examined and it was similar to basal translation seen in the absence of $\mathrm{KCl}$ (Fig. 1A-C). To validate the aforementioned, we examined activitydependent changes in expression of the cytoskeletal regulatory protein, Arc, by immunoblotting because it is used as a marker for coupling neuronal activity to synaptic plasticity $(5,17,29)$. We observed increased levels of Arc protein after 

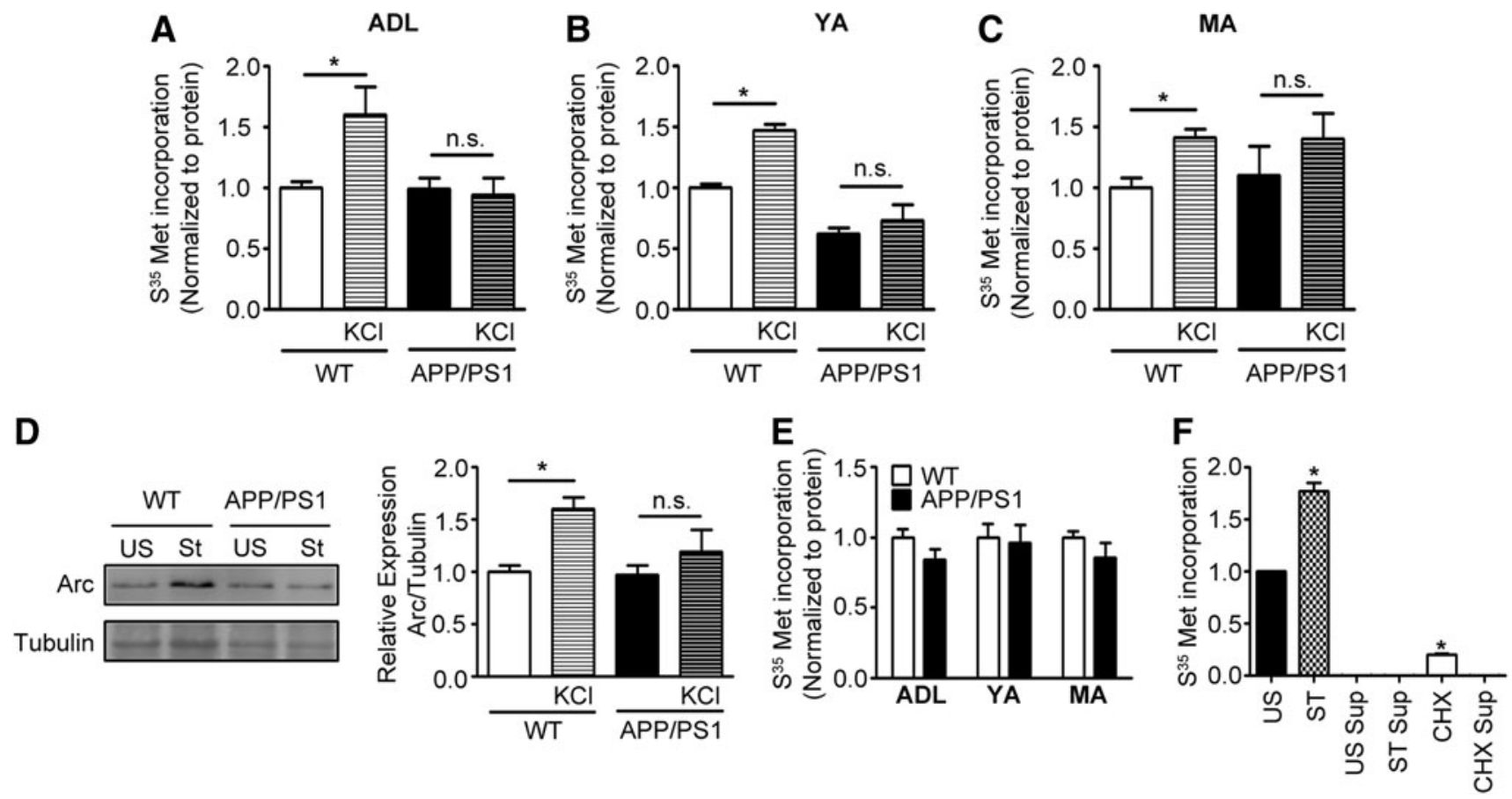

FIG. 1. Local activity-dependent protein translation at the synapse is diminished in APP/PS1 mice from adolescence. Protein translation in synaptoneurosomes from WT and APP/PS1 mice after KCl stimulation was measured as $\mathrm{S}^{35}$. methionine incorporation. Stimulation of protein translation in synaptoneurosomes in the presence of $\mathrm{KCl}$ was abolished in ADL 1 month old; (A), YA; 3 months; (B) and MA; 9-12 months; (C) APP/PS1 mice. KCl stimulation of synaptoneurosomes increased Arc expression levels in 1-month-old WT mice, but no increase was observed in age-matched APP/ PS1 mice (D). See Supplementary Fig. S6 for full blots (Supplementary Data are available online at www.liebertpub.com/ ars). Protein translation measured as $\mathrm{S}^{35}$-methionine incorporation in PNS fraction was unaffected in APP/PS1 mice at all ages examined when compared with that in age-matched controls (E). Protein translation inhibitor CHX abolished $\mathrm{S}^{35}$ methionine incorporation (F). "Sup" represents the last wash of the respective TCA-precipitated samples and had little measurable radioactivity indicating removal of all unbound $\mathrm{S}^{35}$-methionine. Data are represented as mean $\pm \operatorname{SEM}(n=4$ mice $)$ and $*$ denotes values significantly different from corresponding controls $(p<0.05)$. ADL, adolescent; CHX, cycloheximide; MA, middle aged; TCA, trichloroacetic acid; YA, young adult; WT, wild type; n.s., not significant; Sup, supernatant.

$\mathrm{KCl}$ stimulation of synaptoneurosomes isolated from 1month old WT mice, but not from APP/PS1 mice (Fig. 1D and Supplementary Fig. S6). Surprisingly, protein translation in cortical PNS samples of APP/PS1 mice as assessed by $\mathrm{S}^{35}$ methionine incorporation remained unaltered at all ages examined (Fig. 1E).

\section{Akt1-mTOR signaling is diminished presymptomatically in synaptosomes of APP/PS1 mouse brain cortex from 1 month of age}

Akt1-mTOR signaling is a key component of activitydependent local dendritic protein translation (15, 44, 48). The pathway is critical in regulating mRNA translation initiation, thus influencing cell growth in general, and dendritic arborization during neuroplasticity in particular (22). Hence, to understand the molecular mechanisms behind the loss of activity-dependent protein translation at synapses, we assessed the status of several players of Akt1mTOR signaling cascade in synaptosomes isolated from APP/PS1 mice.

First we assessed the levels of pAkt1 in synaptosomes of APP/PS1 mice at 1, 3, and 9-11 months of age and compared them with the levels in age-matched WT controls. As Akt1 is activated by phosphorylation at Thr308 and Ser473, we an- alyzed the levels of both pAkt1 forms. We observed considerable loss of pAkt1 at both Thr308 and Ser473 in synaptosomes of APP/PS1 mice compared with WT mice at all ages examined (Fig. 2A, B and Supplementary Figs. S1A, B, S7-S10, S25, and S26). Loss of pAkt1 in synaptosomes of transgenic mice was confirmed by assaying Akt1 kinase activity using recombinant truncated GSK $3 \beta$ as substrate after immunoprecipitation of Akt1 from synaptosomes (Fig. 2C and Supplementary Figs. S11 and S12). Our results demonstrate that Akt1 signaling is reduced very early at 1 month of age and is sustained till 9-11 months, when the behavioral and pathological symptoms of AD are seen.

mTOR is a rapamycin-sensitive serine/threonine protein kinase that is downstream to Akt1 and is indirectly activated by pAkt through phosphorylation of TSC $1 / 2$, the inhibitory regulator of mTOR (18). Activated mTOR, in turn, stimulates cap-dependent protein synthesis in neurons by phosphorylating several mRNA translation factors, including eukaryotic initiation factor 4E-binding protein-1 (4E-BP1) and p70 ribosomal S6 kinase [S6K; (34)].

The levels of pmTOR (Ser2448) were decreased in cortical synaptosomes isolated from 1, 3, and 9-month-old APP/PS1 mice compared with those of age-matched WT controls (Fig. 3A and Supplementary Figs. 2A, S13, S14, and S27). Moreover, concomitant decrease in levels of downstream effectors 

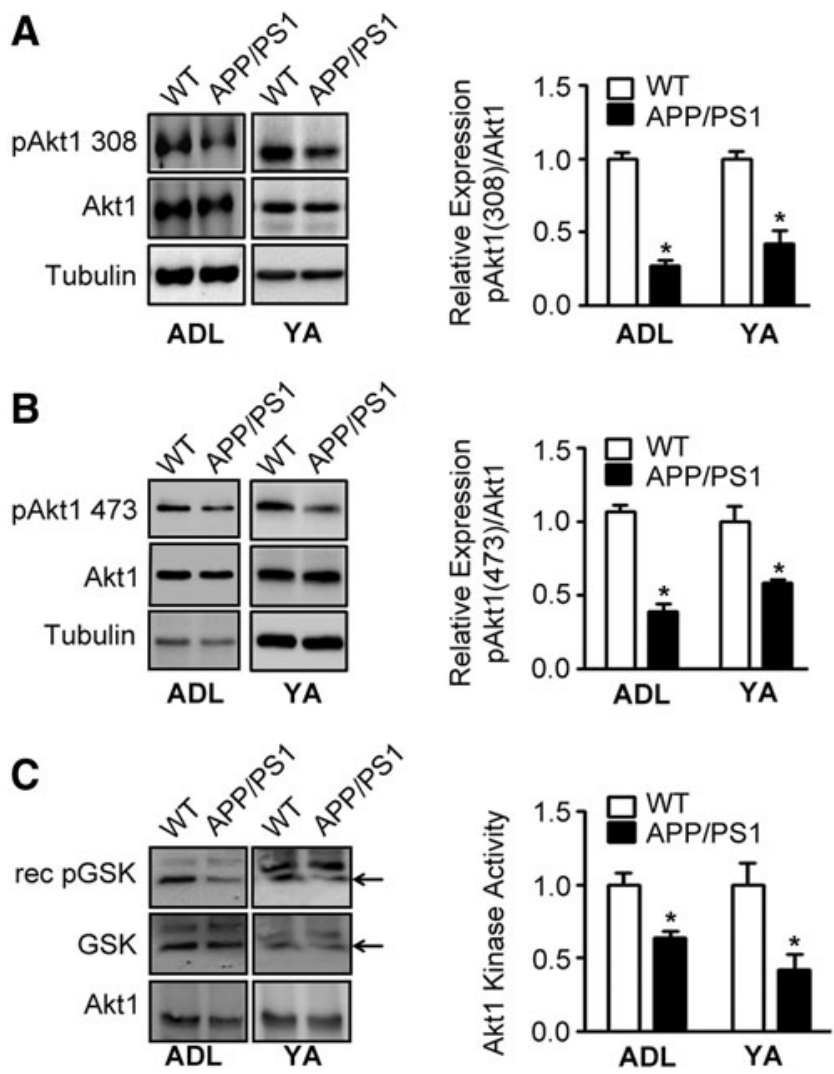

FIG. 2. Akt1 phosphorylation and its kinase activity are decreased in synapses of APP/PS1 mice early in the disease pathogenesis. Levels of both the phosphorylated forms of Akt1 [Thr308; (A) and Ser473; (B)], which are critical for its kinase activity, are reduced in synaptosomes isolated from ADL and YA APP/PS1 mice compared with those from age-matched WT controls. Akt1 kinase activity was measured by immunoblot-based assay of phosphorylation of the Akt1 substrate, recombinant-truncated GSK [rec GSK; (C)]. Cortical synaptosomes from APP/PS1 mice have reduced Akt1 activity when compared with those from WT controls at all ages examined. Values are mean \pm SEM $(n=6$ mice) and $*$ denotes values significantly different from corresponding controls $(p<0.05)$. See also Supplementary Fig. S1.

of pmTOR, namely pS6K (Thr389; Fig. 3B and Supplementary Figs. S2B, S15, S16, and S28) and p4EBP1 (Thr37/ 46; Fig. 3C and Supplementary Figs. S2C, S17, S18, and S29 and), was observed in synaptosomes of APP/PS1 mice at all ages examined. In conclusion, dysregulation of Akt1mTOR signaling occurring at the synapses of APP/PS1 mice from an early age of 1 month onward could potentially contribute to the reduction in activity-dependent protein translation observed earlier (Fig. 1).

\section{Increased oxidation of Akt1 leads to increased association with the phosphatase, PP2A}

To address the mechanism for downregulation of Akt1 phosphorylation and thence its kinase activity, we first measured total $\mathrm{A} \beta 42$ levels in cortical homogenates from APP/PS1 mice, and also examined the presence of $\mathrm{A} \beta 42$ oligomers in synaptosomes. Total A $\beta 42$ levels were 1.35 and $5.30 \mathrm{pmol} / \mathrm{mg}$ protein in the cortical lysates of ADL (1-1.5 months old) and YA (3-4 months old) APP/PS1 mice, respectively, which were 6.43 and 13.95 -fold more than the respective age-matched WT mice (Fig. 4A). Using immunoblotting, we detected appreciable amounts of trimers of $\mathrm{A} \beta$ in cortical synaptosomes prepared from APP/PS1 mice from age 1 month onward, whereas synaptosomes from WT mice had negligible amounts of A $\beta$ oligomers (Fig. 4B and Supplementary Figs. S19, S20), indicating that $\mathrm{A} \beta 42$ is present in appreciable quantities at the synapse even in the presymptomatic stage of the disease.

Akt1 is a redox-sensitive protein and its kinase activity is regulated by the redox milieu $(1,11)$. Oxidation of the cysteine moieties at 296 and 310 positions (flanking the regulatory domain of Akt1) leads to its increased association with the protein phosphatase, PP2A, resulting in dephosphorylation and termination of kinase activity of Akt1 $(1,11)$. Oxidative stress has been proposed to be a critical mechanism contributing to $\mathrm{AD}$ pathogenesis, and $\mathrm{A} \beta 42$ peptide is known to generate ROS $(7,31)$. Indeed, we detected increased ROS levels in synaptosomes isolated from APP/PS1 mice brain cortices at 1 and 3 months (Fig. 4C and Supplementary Fig. S4). Furthermore, using a combination of $2^{\prime}, 7^{\prime}-$ dichlorodihydrofluorescein diacetate (DCFH-DA) reaction and Homer1 immunohistochemistry, we were able to detect significantly higher amounts of ROS in both soma and neurites of primary cortical neurons from APP/PS1 mice than those from WT mice (Fig. 4D and Supplementary Fig. S5).

We hypothesized that decrease in synaptic Akt1 activity in APP/PS1 mice could be a consequence of increased Akt1 oxidation. We assessed the levels of reduced Akt1 after its derivatization with 4-acetamido-4'-maleimidylstilbene-2,2'disulfonic acid, disodium salt (AMS). Reduced Akt1 levels were found to be diminished in synaptosomes (Fig. 4E and Supplementary Fig. S21) isolated from 1-month-old APP/ PS1 mice, indicating enhanced oxidation of Akt1 at the synapse. AMS-derivatized blots were normalized to SNAP29 because of its lack of cysteine residues, which could potentially react with AMS. Importantly, we also observed enhanced association of Akt1 with PP2A in synaptosomes from 1-month-old APP/PS1 mice (Fig. 4F and Supplementary Figs. S22 and S23), which persisted up to 9 months of age (Fig. 4G and Supplementary Fig. S24), suggesting that increased oxidation of Akt1 could indeed have resulted in its increased affinity for PP2A, thereby contributing to loss of its phosphorylation and kinase activity (Fig. 2A-C).

\section{Overexpression of myristoylated Akt1 rescues the deficits in brain-derived neurotrophic factor-stimulated protein translation in primary cortical neurons derived from APP/PS1 mice}

Primary cortical neurons were isolated from WT and APP/ PS1 mice and brain-derived neurotrophic factor (BDNF)stimulated protein translation was measured using puromycin incorporation as a marker. $\mathrm{BDNF}$ and not $\mathrm{KCl}$ was employed for stimulation of primary neurons to prevent the consequences of osmotic changes in extracellular milieu that have undesirable effects on cultured neurons.

Treatment with BDNF caused stimulation of protein translation in primary neurons obtained from WT mice but not from APP/PS1 mice, observed as increased puromycin incorporation (Fig. 5). This deficit in stimulated protein 

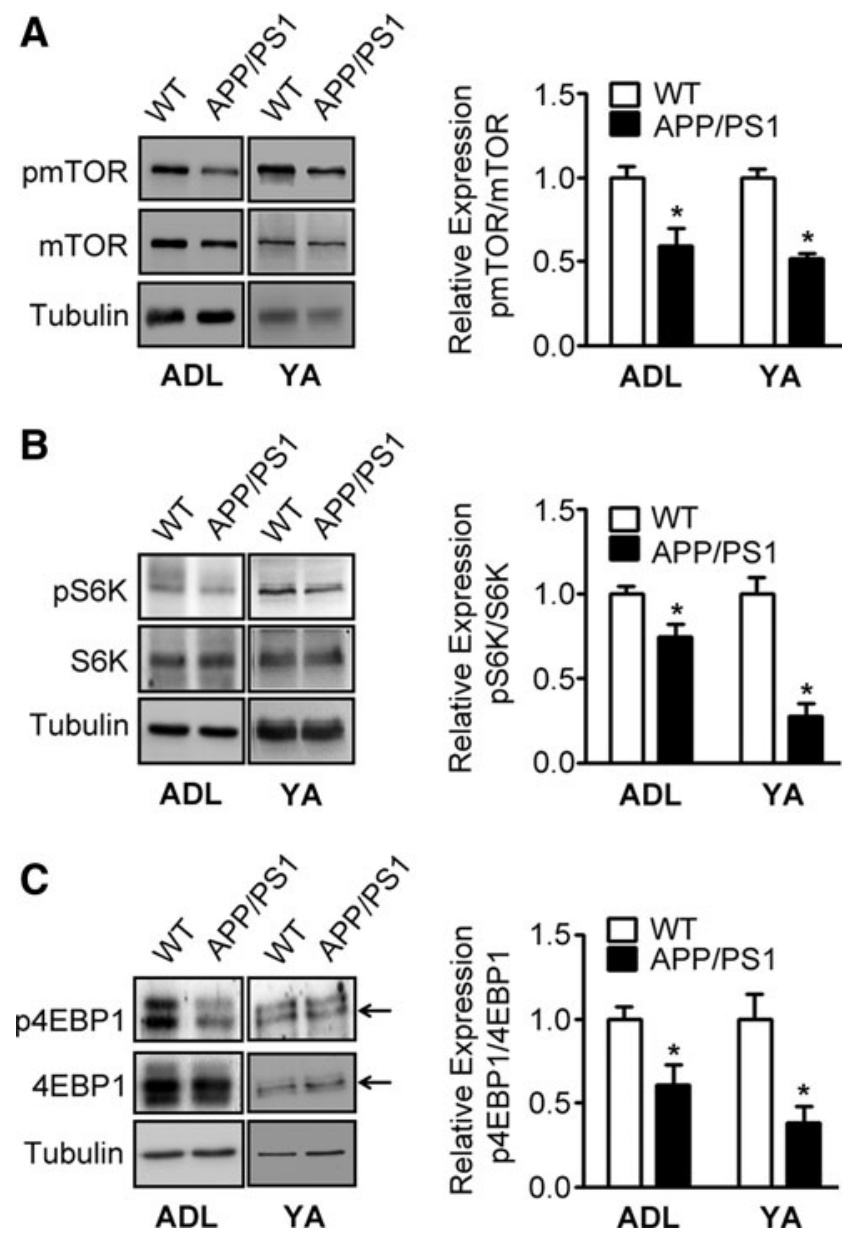

FIG. 3. mTOR signaling is disrupted in synaptosomes from ADL and YA APP/PS1 mice. Levels of pmTOR (Ser2448); (A) were decreased in synaptosomes from ADL and YA APP/PS1 mice as compared with those from agematched WT controls. Similar decreases in phosphorylated forms of two mTOR substrates: pS6K at Thr389 (B) and p4EBP1 at Thr46/47 (C), were observed in synaptosomes of APP/PS1 mice at all ages examined. Values are mean \pm SEM ( $n=6$ mice) and * denotes values significantly different from corresponding controls $(p<0.05)$. See also Supplementary Fig. S2. pmTOR, phosphorylated mTOR.

translation was observed in both soma and neurites of APP/ PS1 neurons.

Next, we overexpressed myristoylated Akt1 [myr-Akt1; a constitutively active Akt1 form (42)] in primary neurons obtained from APP/PS1 mice using lentiviral transduction (Supplementary Fig. S3). Stimulated protein translation after BDNF treatment of APP/PS1 neurons transduced with myrAkt1 was similar to that of WT neurons (Fig. 5). Thus, myrAkt1 overexpression was able to rescue the deficit seen in primary neurons from APP/PS1 mice.

\section{Activity-dependent protein translation is diminished in synaptoneurosomes isolated from postmortem brain neocortical samples from human brains}

To extend our findings using APP/PS1 mice, we sought to assess protein translation rates in synaptoneurosomes iso- lated from human postmortem tissue. Synaptoneurosomes prepared from postmortem frozen human brain tissues have previously been shown to have intact mRNAs and protein translation machinery and have also been used successfully for in vitro translation assays (49). Hence, we measured protein translation rates in synaptoneurosomes and PNS isolated from postmortem brain prefrontal neocortical tissue samples of persons with $\mathrm{AD}$ using $\mathrm{S}^{35}$-methionine incorporation assay and compared them with samples from subjects with no cognitive impairment (NCI) and mild cognitive impairment (MCI). Basal protein translation rates in synaptoneurosomes were similar among $\mathrm{AD}, \mathrm{MCI}$, and $\mathrm{NCI}$ groups (Fig. 6A, B). Upon stimulation of synaptoneurosomes, we observed increased $\mathrm{S}^{35}$-methionine incorporation as has been previously reported (49) for samples from both NCI and MCI subjects (Fig. 6A, B). However, activity-dependent protein translation was compromised in synaptoneurosomes prepared from $\mathrm{AD}$ subjects (Fig. 6A, B). In contrast, protein translation as measured by $\mathrm{S}^{35}$-methionine incorporation in PNS fraction was unaltered in subjects with $\mathrm{AD}$ compared with that in subjects with NCI or MCI (Fig. 6C, D).

\section{Discussion}

Synaptic dysfunction is a primary player in the pathogenesis of $\mathrm{AD}$; however, the underlying mechanisms are not clear. Activity-dependent synaptic protein translation is a robust indicator of synaptic function and plasticity $(10,36$, 48). Dysfunction of activity-dependent translation very early in the pathogenesis of $\mathrm{AD}$ would have far-reaching implications for synapse maintenance and plasticity culminating into deficits in memory and cognitive abilities. We, therefore, examined the status of activity-dependent translation in synaptoneurosomes from APP/PS1 mice to determine whether this was compromised in the disease process. We observed significantly compromised KCl-stimulated activity-dependent protein translation in synaptoneurosomes isolated from APP/ PS1 mice from 1 month onward (soon after the mice were weaned from their mothers), which persisted up to MA (Fig. 1A-C). We further demonstrate that ROS-mediated thiol oxidation of Akt1 in the synaptosomes leads to deficient Akt1 kinase activity, resulting in decreased Akt1-mTOR signaling and consequent loss of activity-dependent protein translation.

Akt1-mTOR signaling has been shown to be critical for activity-dependent local dendritic translation (15, 44, 48). Indeed, loss of activity-dependent translation was accompanied by diminished Akt1-mTOR signaling in synaptosomes seen as decreased levels of pmTOR and its downstream substrates, pS6K and p4EBP1 (Fig. 3 and Supplementary Fig. S2). Furthermore, activity of Akt1, the upstream kinase that activates mTOR by phosphorylating TSC1/2 (inhibitory regulator of mTOR), was decreased as evidenced by loss of kinase activity and levels of pAkt1 (Thr308 and Ser473; Fig. 2 and Supplementary Fig. S1). In conclusion, using a mouse model of $\mathrm{AD}$, we demonstrate that activity-dependent translation is inhibited in synaptoneurosomes early in the pathogenesis of AD because of loss of Akt1 kinase activity and resultant inhibition of Akt1 signaling. This is supported by our data showing reversal of this deficit by ectopic overexpression of persistently active Akt1. Thus, loss of Akt1, the major upstream kinase of this pathway, could potentially be the primary cause of dysfunctional protein synthesis seen in 
A

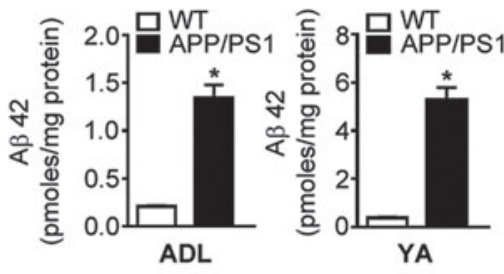

.

Homer1
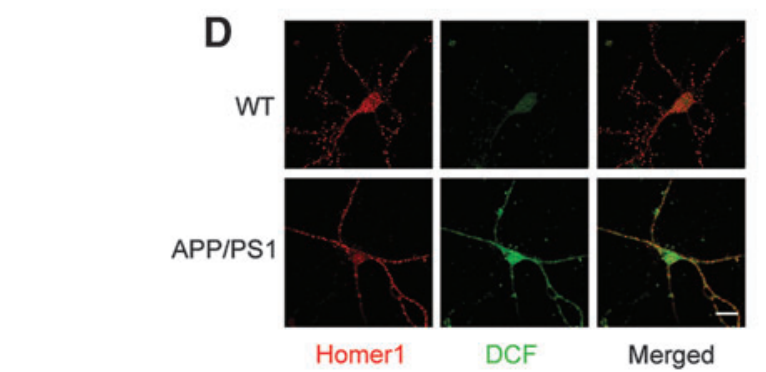

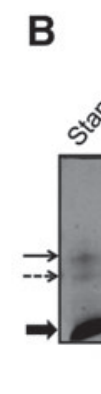

B

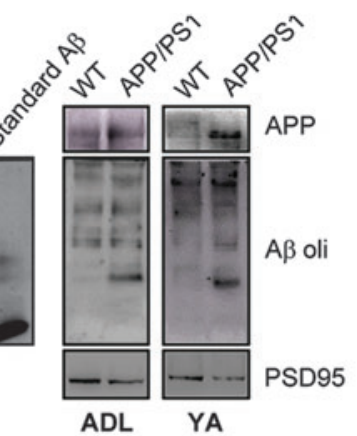

C

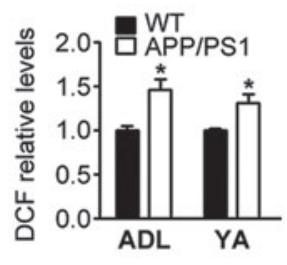

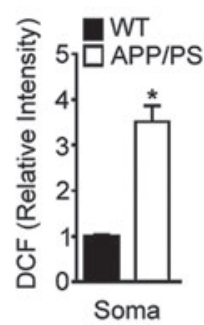

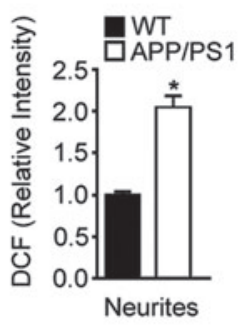

E
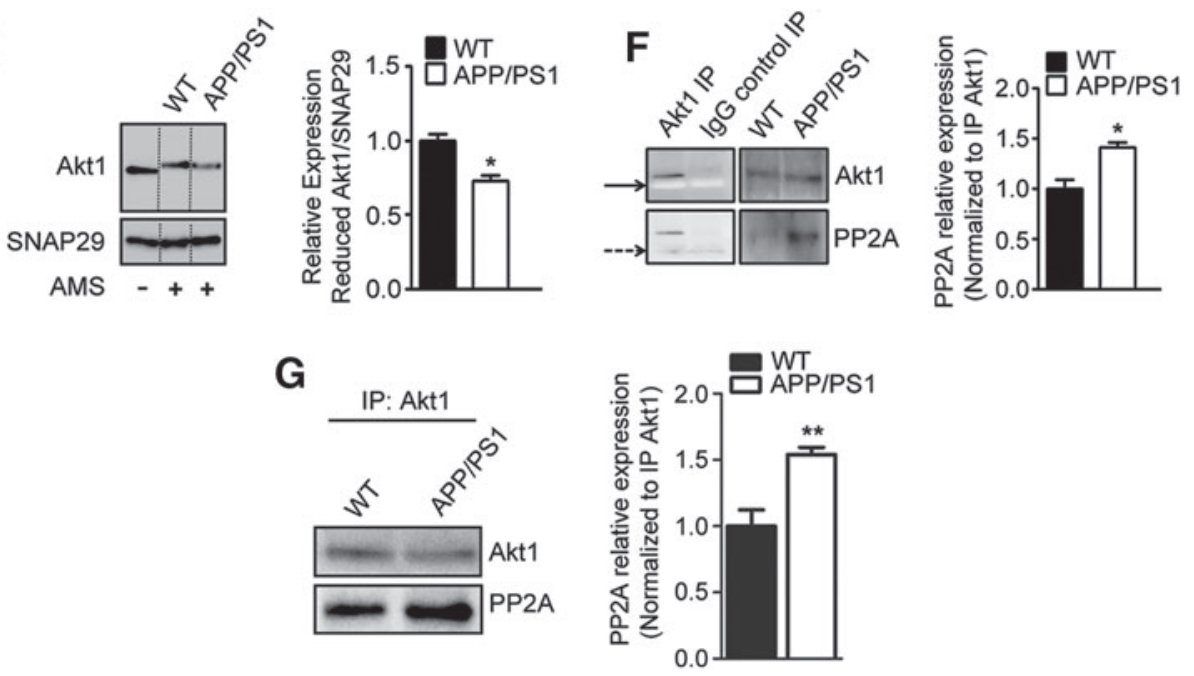

FIG. 4. Increased oxidation of Akt1 and its increased affinity for PP2A are observed in synaptosomes of APP/PS1 mice. A $\beta 42$ levels in cortical homogenates from different ages of WT and APP/PS1 mice measured using ELISA is depicted for ADL (1-1.5 months old) and YA (3-4 months old) mice (A). Immunoblotting provides evidence for increased accumulation of oligomeric $\mathrm{A} \beta$ in synaptosomes from ADL and YA APP/PS1 mice (B). Immunoreactive signals for PSD95 were used to normalize the blots. The leftmost panel with the synthetic $\mathrm{A} \beta$ standard is shown as a reference. Treatment of synaptosomes isolated from cortices of ADL and YA APP/PS1 mice with DCFH-DA leads to increased generation of DCF fluorescence when compared with that from age-matched controls (C). See Supplementary Fig. S4 also. Primary cortical neurons were treated with DCFH-DA and the resultant DCF fluorescence (green) was observed along with immunostaining for Homer1 (red; D). Increased colocalization of DCF with Homer1 is observed, indicating extensive ROS levels in neurites and terminals of APP/ PS1 cortical neurons, whereas WT cortical neurons show very little staining for ROS ( $n=7-11$ independent cultures). Scale bar is $20 \mu \mathrm{m}$. See Supplementary Fig. S5. Reduced Akt1 levels assayed as AMS derivatized protein were decreased in synaptosomes isolated from ADL (1 month old) APP/PS1 mice when compared with those from age-matched controls (E). Immunoprecipitated Akt1 from synaptosomes of 1 month (F) and 9 months (G) old APP/PS1 mice had increased affinity for the phosphatase, PP2A. Values are mean $\pm \operatorname{SEM}(n=4$ mice $)$ and $*$ denotes values significantly different from corresponding controls $(p<0.05)$.** denotes values significantly different from corresponding controls $(p<0.01)$.

synaptoneurosomes. Furthermore, we also observed attenuation of synaptic Akt1 signaling and activity-dependent translation in synaptoneurosomes from neocortical tissue samples of postmortem brains of AD patients (Fig. 6).

Interestingly, basal protein translation seen in the absence of $\mathrm{KCl}$ was not significantly different in synaptoneurosomes of both APP/PS1 mice and postmortem AD brains. This indicates that basal translation may potentially occur even with limiting amounts of Akt1-mTOR signaling. Under basal conditions, pAkt1 levels, per se, may not be rate limiting, whereas enhanced translation occurring after neuronal activity, such as $\mathrm{KCl}$ stimulation, would require optimal levels 

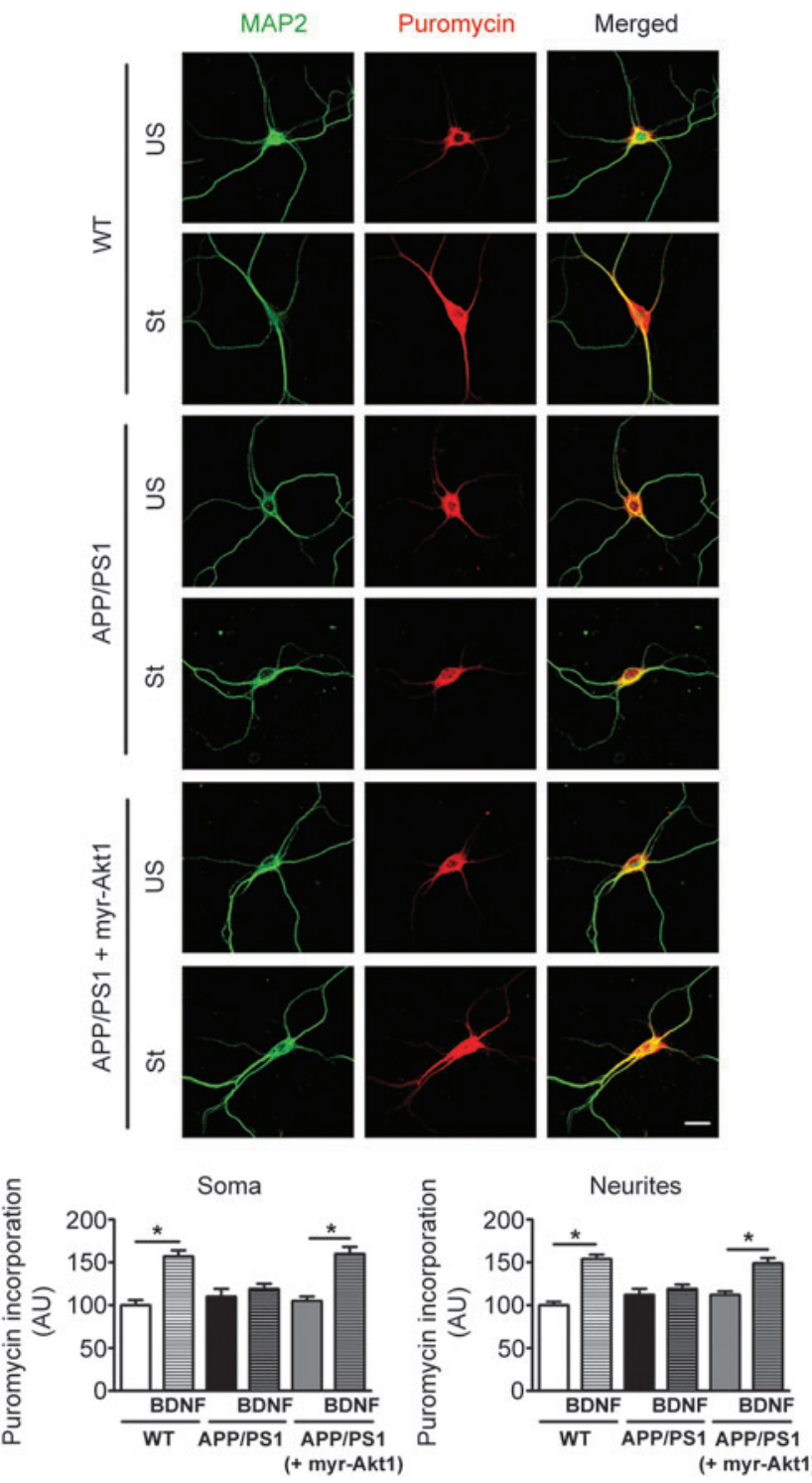

FIG. 5. Deficit in BDNF-stimulated protein translation in cultured cortical primary neurons from APP/PS1 mice is rescued by myristoylated Akt1 overexpression. Increased protein translation was observed in both soma and neurites of primary cortical neurons isolated from WT mice after BDNF stimulation. Stimulation of protein translation at soma and neurites after BDNF treatment was not observed in primary cortical neurons isolated from APP/PS1 mice. Overexpression of myristoylated Akt1 (myr-Akt1), which is constitutively active, rescues the compromised stimulated protein translation in APP/PS1 neurons. Values are mean \pm SEM ( $n=31-36$ neurons) and $*$ denotes values significantly different from corresponding controls $(p<0.05)$. Scale bar is $20 \mu \mathrm{m}$. See Supplementary Fig. S3. BDNF, brain-derived neurotrophic factor.

of activated Akt1 (including de novo phosphorylation) at the site of translation, which is not available during $\mathrm{AD}$ pathogenesis. Indeed, neuronal activity is known to robustly stimulate local Akt1 signaling (12). This is supported by our observation wherein overexpression of constitutively active myristoylated Akt1 rescues the deficits in activitydependent translation (Fig. 5).
A

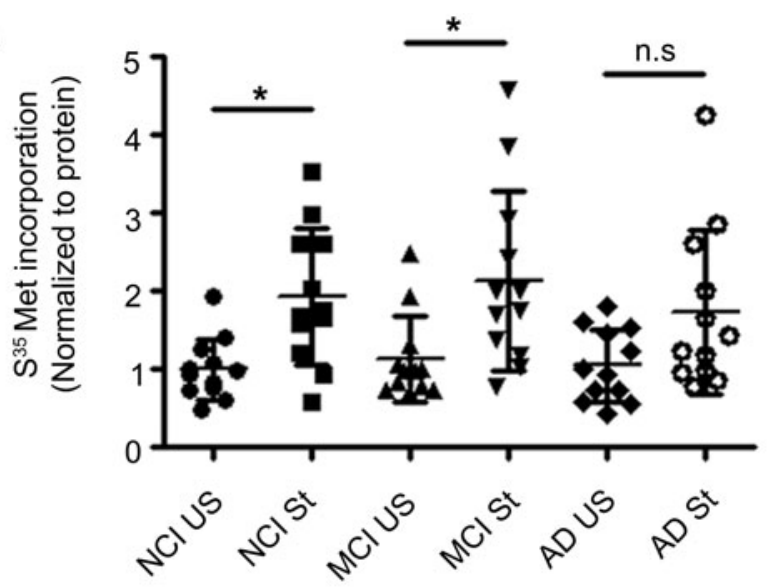

B

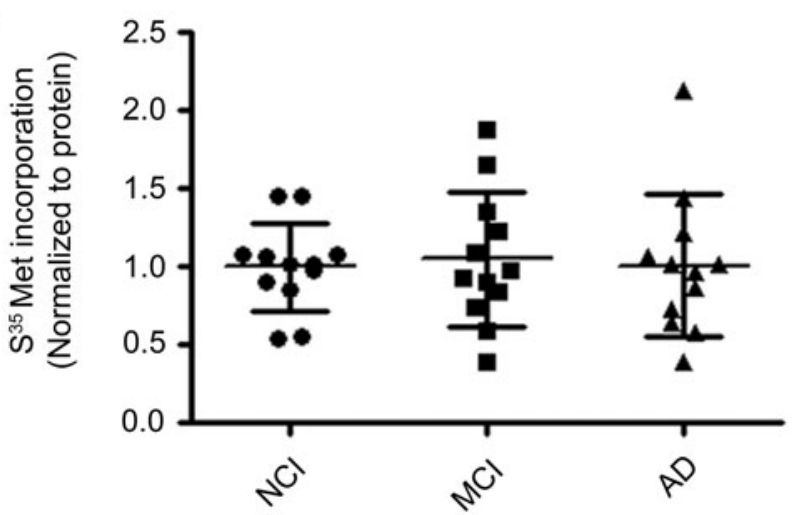

FIG. 6. Activity-dependent protein translation at the synapses disrupted in frontal neocortical samples from postmortem brains of AD patients. Although basal protein translation in neocortical synaptoneurosomes was unaffected in tissue samples from postmortem brains of patients with $\mathrm{AD}$, stimulated protein translation in the presence of $\mathrm{KCl}$ was attenuated in $\mathrm{AD}$ patients compared with samples from subjects with MCI or subjects with NCI (A). S $^{35}$ methionine incorporation was unaffected in PNS fractions isolated from postmortem AD brains when compared with that from subjects with NCI and MCI (B). (A) and (B) show individual values for synaptoneurosomes and PNS fractions, respectively. Values are mean $\pm \mathrm{SD}(n=12$ subjects for each group) and $*$ denotes values significantly different from corresponding controls $(p<0.05)$. MCI, mild cognitive impairment; NCI, no cognitive impairment; PNS, postnuclear supernatant. n.s, not significant.

An interesting aspect of our study is that the presence of A $\beta 42$ oligomers in synaptosomes from mice aged 1 month onward (Fig. 4B) indicates that even if A $\beta 42$ accumulation in the brain does not reach pathogenic levels, the presence of toxic $\mathrm{A} \beta 42$ oligomers at the synapse can potentially disrupt synaptic functions, thus initiating pathogenic processes before overt symptoms appear. Excessive ROS generation has been considered to be one of the early events that contribute to $\mathrm{AD}$ pathogenesis $(7,31)$. We quantified ROS in synaptosomes isolated from cortices of APP/PS1 mice and observed increase in ROS levels in synaptosomes from APP/PS1 mice from age 1 month onward (Fig. 4C). Cysteine residues at 296 and 310 positions in Akt1 are very sensitive to redox modulation, and such redox modifications have been shown to 
increase its association with the phosphatase PP2A, leading to its dephosphorylation (1). Hence, we quantified reduced levels of Akt1 and found they were decreased in synaptosomes isolated from 1-month-old APP/PS1 mice compared with those from WT controls (Fig. 4E). As expected, this led to increased association of synaptosomal Akt1 with PP2A in APP/PS1 mice (Fig. 4F, G), leading to compromised Akt1 kinase activity and consequently Akt1-mTOR signaling.

Thus, using a mouse model of AD, namely APP/PS1 mice, we demonstrate for the first time that activity-dependent translation is inhibited selectively in synaptoneurosomes early in the pathogenesis of AD because of ROS-mediated loss of Akt1 kinase activity and resultant inhibition of mTOR signaling. Importantly, we could also rescue the deficits in BDNF-stimulated protein translation by overexpression of myristoylated Akt1 in primary cortical neurons from APP/PS1 mice (Fig. 5). Thus, loss of Akt1, the major upstream kinase of Akt1-mTOR pathway, is a primary cause of dysfunctional protein synthesis seen in synaptoneurosomes in AD.

Another important aspect of this study is that regulation of Akt1 kinase, involved in cell survival signaling, is different and manifests according to age and/or extent of $\mathrm{A} \beta$ accumulation in human patients (28). It is important to note that most prior studies on Akt1-mTOR signaling in AD models or human postmortem tissues have been carried out using whole cell lysates and we do not have a clear understanding of the status of Akt1-mTOR signaling at the synapse in AD pathogenesis, especially during the early stages of disease progression. Moreover, previous studies have not delineated the underlying mechanisms involved in disrupted Akt1mTOR signaling in AD. Hence in this study, we provide evidence of redox-mediated disruption of synaptic Akt1 function early in the disease progression, which persists up to MAs when overt symptoms of AD become evident in the mouse model.

Our results are in agreement with earlier reports that enhancing Akt1 kinase activity offers protection in cellular and animal models of neurodegeneration, often attributed to its prosurvival function. Indeed, increased expression of recombinant Akt1 or active pAkt1 has been shown to underlie the neuroprotection mediated by neurotrophins (33), estrogen (43), and lipoic acid (38) in AD model systems. Moreover, our findings are significant because synaptic plasticity and its consolidation are spatially limited and require both precise and dynamic changes in protein translation, trafficking, and organization within the microdomain of the synapse. Spatiotemporal regulation of synaptic proteins (namely neurotransmitter receptors, signaling proteins, and cytoskeletal and scaffold elements) is critical for precise functioning and plasticity of synapse. This is, in part, dependent on dendritic mRNA transport and its local translation at the synapse (48). Furthermore, dysregulation of the plastic changes in neurotransmission through dysfunction of the machinery used for activity-dependent synaptic translation could potentially culminate into cognitive deficits $(6,14,21,48)$. It is not surprising then that dysregulated activity-driven synaptic translation has been implicated in disorders such as Fragile $\mathrm{X}$ syndrome and autism (47). In fact, several cases of autism spectrum disorders have been found to be associated with mutations in genes encoding components of the Akt1 signaling pathway (24).
In conclusion, we demonstrate that increase in ROS levels in synaptosomes occurs very early in the disease process, leading to loss of Akt1 kinase activity and resulting in deficiency of activity-dependent synaptic protein translation, with potentially far-reaching implications for synaptic plasticity, learning, and memory. Furthermore, manifestation of these deficits very early in life indicates that the prodromal stage of $\mathrm{AD}$ may start very early and thus provides a window for intervention, particularly in familial AD cases.

\section{Methods \\ Antibodies and reagents}

Primary antibodies against pAkt1 (Ser473), pAkt1 (Thr308), Akt1, pGSK3 $\beta$ (Ser9), GSK3 $\beta$, pmTOR (Ser2448), mTOR, pS6K (Thr389), S6K, p4EBP1 (Thr46/47), and 4EBP1 were purchased from Cell Signaling Technology. Anti-glycogen synthase kinase (GSK) antibody was from Santa Cruz Biotechnology; anti-Arc, anti-SNAP29, and anti-MAP2 antibodies were from Abcam; anti-Homer1 antibody was from Synaptic Systems; anti-Puromycin antibody was from Millipore; and anti- $\beta$-tubulin antibody was from Sigma-Aldrich. Akt1 was immunoprecipitated using Dynabeads A (Life Technologies) and Akt1 kinase assay was performed using the nonradioactive kinase assay kit from Cell Signaling Technology. AMS, a thiol reactive reagent used for derivatization of protein samples for redox immunoblots, was procured from Life Technologies. Antibodies against A $\beta 42$ : 12F4 (monoclonal) and H43 (polyclonal), were procured from BioLegend and Santa Cruz, respectively. Antibody against APP (epitope 3-8) 6E10 was procured from BioLegend. 3,3',5,5'-Tetramethylbenzidine (TMB) substrate kit and secondary antibodies: anti-rabbit and anti-mouse conjugated with horse-radish peroxidase (HRP), were purchased from Vector Laboratories. $S^{35}$-L-methionine was procured from Board of Radiation and Isotope Technology, India. HEK293T cells were procured from American Type Culture Collection (ATCC). All other chemicals and reagents used were of analytical grade and obtained from either SigmaAldrich or Merck.

\section{Animals}

Transgenic mice B6C3-Tg [APP $\left.{ }^{\text {Swe }} / \mathrm{PS} 1 \Delta \mathrm{E} 9\right) 85 \mathrm{Dbo} / \mathrm{J}$; www.jax.org/strain/005864; (4)] were procured from Jackson Laboratory, and bred at our central animal facility. Animals were genotyped for the presence of transgene as described in detail previously (41). Three age groups of male APP/PS1 mice, 1-1.5 months (adolescent) and 3-4 months (YA), both of which do not show any overt behavioral or pathological phenotype of AD, and 9-12 months old (MA), which have behavioral deficits and plaque pathology, were used. Age-matched male WT littermates were used as controls. All experiments involving animals were performed in accordance with institutional guidelines for the use and care of animals under approval of the animal ethics committee. All efforts were made to minimize animal suffering and to reduce the number of animals used.

\section{Human tissues}

Frontal neocortical tissue from postmortem brains of agematched persons with $\mathrm{AD}$ dementia and MCI and control 
subjects with NCI were procured from Rush Alzheimer's Disease Centre, Chicago. All participants signed an informed consent as well as an Anatomical Gift Act for brain donation. The study was approved by the Institutional Review Board of Rush University Medical Center. All experiments involving human postmortem tissues were performed in accordance with institutional guidelines and after approval from the ethics committee. Details of the clinical and neuropathological evaluation have been previously reported (2a).

\section{Synaptoneurosome preparation and $S^{35}$-methionine incorporation assay}

Preparation of synaptoneurosomes from mouse cortical tissue (32) or neocortical tissue samples from postmortem human brain (49) and $\mathrm{S}^{35}$-methionine incorporation assay were performed as described previously (32). In brief, tissue was homogenized in translation buffer containing $118 \mathrm{mM}$ $\mathrm{NaCl}, 4.7 \mathrm{~m} M \mathrm{KCl}, 1.2 \mathrm{~m} M \mathrm{MgSO}_{4}, 2.5 \mathrm{~m} M \mathrm{CaCl}_{2}, 1.53 \mathrm{~m} M$ $\mathrm{KH}_{2} \mathrm{PO}_{4}, 212.7 \mathrm{~m} M$ glucose, and $1 \mathrm{~m} M$ 1,4-dithiothreitol (DTT) (pH 7.4), and supplemented with protease and phosphatase inhibitors, $200 \mu \mathrm{g} / \mathrm{ml}$ chloramphenicol, and $30 \mathrm{U} / \mathrm{ml}$ RNAse inhibitor. The homogenate was then passed sequentially through two $100 \mu \mathrm{m}$ and one $10 \mu \mathrm{m}$ membrane filters (Millipore). The filtrate obtained was then centrifuged at $1500 \mathrm{~g}$ at $4^{\circ} \mathrm{C}$ for $10 \mathrm{~min}$ and pellet containing synaptoneurosomes was resuspended in translation buffer. Stimulation of synaptoneurosomes was carried out by incubation with $50 \mathrm{mM} \mathrm{KCl}$ at $37^{\circ} \mathrm{C}$ for $15 \mathrm{~min}$ in the presence of $50 \mu \mathrm{Ci}$ $\mathrm{S}^{35}$-L-methionine. Unstimulated samples were incubated with $50 \mu \mathrm{Ci} \mathrm{S}{ }^{35}$-L-methionine alone. In certain instances, synaptoneurosomes were preincubated with $50 \mu \mathrm{g} / \mathrm{ml}$ cycloheximide at $37^{\circ} \mathrm{C}$ for $15 \mathrm{~min}$ to block protein translation. Samples were then precipitated with equal volume of icecold $10 \%(\mathrm{w} / \mathrm{v})$ TCA. Protein pellets were washed extensively with ice-cold 5\% (w/v) TCA followed by washes with ice-cold methanol until the washes showed no detectable radioactivity. The washed pellets were either resuspended in $0.1 \mathrm{~N} \mathrm{NaOH}$ for liquid scintillation counting or suspended in Laemmeli's buffer for sodium dodecyl sulfate polyacrylamide gel electrophoresis (SDS-PAGE) and immunoblotting against Arc.

\section{Synaptosomal preparation}

Synaptosomes were prepared as described previously (3) with some modification. In brief, brain tissue was homogenized in 10 volumes of homogenization buffer ( $5 \mathrm{~m} M$ HEPES buffer, $\mathrm{pH} 7.4$, containing $0.32 M$ sucrose, $50 \mathrm{~m} M$ sodium fluoride, $1 \mathrm{~m} M$ sodium orthovanadate, $2 \mu \mathrm{g} / \mathrm{ml}$ aprotinin, $10 \mu \mathrm{g} / \mathrm{ml}$ leupeptin, $7 \mu \mathrm{g} / \mathrm{ml}$ pepstatin $\mathrm{A}, 100 \mu \mathrm{g} / \mathrm{ml}$ of phenylmethanesulfonyl fluoride (PMSF), and $10 \mu \mathrm{l} / \mathrm{ml}$ of protease inhibitor cocktail) in a Potter-Elvehjem homogenizer. The homogenate was centrifuged at $1000 \mathrm{~g}$ at $4^{\circ} \mathrm{C}$ for $10 \mathrm{~min}$ and the PNS was obtained. PNS prepared from mouse cortex (as already described) was centrifuged again at 12,000 $\mathrm{g}$ at $4^{\circ} \mathrm{C}$ for $15 \mathrm{~min}$, and the pellet was resuspended in $5 \mathrm{mM}$ Tris ( $\mathrm{pH}$ 8.1) containing $0.32 \mathrm{M}$ sucrose along with protease and phosphatase inhibitors. The resuspended pellet was then layered over discontinuous sucrose gradient (0.85-1.0-1.2 $M$ ) and centrifuged at $85,000 \mathrm{~g}$ for $2 \mathrm{~h}$ at $4^{\circ} \mathrm{C}$. Synaptosomal fraction obtained at the interface of 1 and $1.2 \mathrm{M}$ sucrose was collected, washed twice in $5 \mathrm{mM}$ Tris ( $\mathrm{pH} 8.1$ ), and resuspended in homogenization buffer for further experiments.

\section{Enzyme-linked immunosorbent assay}

Total A $\beta 42$ levels in brain were quantitated by enzymelinked immunosorbent assay as previously described (41) using 12F4 as a capture antibody and H43 as a detection antibody. Signal was detected using an HRP-labeled secondary antibody and TMB as a substrate.

\section{Immunoblotting}

Synaptosomal and PNS samples were resolved on SDSPAGE, electroblotted, and immunostained using primary and secondary antibodies. Immunoreactive chemiluminescent signals were detected and the intensities of the bands were quantified using Bio-Rad Imager. In some cases, the samples were denatured with SDS and incubated with $15 \mathrm{~m} M$ AMS for $3 \mathrm{~h}$ at room temperature under nitrogen atmosphere. The reaction was then quenched with $60 \mathrm{~m} M$ glutathione (GSH) and the samples were immunoblotted as already described. SDS-solubilized synaptosomes were also resolved on 10 $20 \%$ tris-tricine gels for separation of A $\beta$ oligomers (40), transferred to PVDF membranes, and probed with $6 \mathrm{E} 10$ antibody that recognizes both APP and A $\beta 42$ species.

\section{Immunoprecipitation of Akt1}

Immunoprecipitation of Akt1 was carried out using Protein A-conjugated Dynabeads (Life Technologies) according to the manufacturer's instructions. In brief, Protein Aconjugated Dynabeads were incubated with anti-Akt1 antibody in PBS (pH 7.4) containing $137 \mathrm{mM} \mathrm{NaCl}, 2.7 \mathrm{mM} \mathrm{KCl}$, $10 \mathrm{~m} M \mathrm{Na}_{2} \mathrm{HPO}_{4}, 2 \mathrm{~m} M \mathrm{KH}_{2} \mathrm{PO}_{4}$, and $0.1 \%$ (v/v) Igepal $\mathrm{CA} 360$ for $3 \mathrm{~h}$ at room temperature. The antibody-linked Dynabeads were washed with PBS and incubated overnight at $4{ }^{\circ} \mathrm{C}$ with synaptosomes in PBS containing $1 \%$ (v/v) Triton $\mathrm{X}-100$ and protease and phosphatase inhibitors. The beads were washed twice with PBS containing $0.5 \%$ (v/v) Igepal CA360 at $4{ }^{\circ} \mathrm{C}$ and eluted using Laemmeli's SDS loading buffer and subjected to SDS PAGE.

\section{Akt1 kinase assay}

Akt1 kinase assay was performed according to the manufacturer's instructions (Cell Signaling Technology). In brief, synaptosomes were incubated with Sepharose beads crosslinked with antibody against pAkt1 (Ser473) at $4^{\circ} \mathrm{C}$ overnight for immunoprecipitation. After washing with PBS, the beads were added to kinase assay buffer containing $25 \mathrm{~m} M$ Tris ( $\mathrm{pH}$ 7.5), supplemented with $25 \mathrm{mM} \mathrm{MgCl} 2$ and $0.2 \mathrm{~m} M$ ATP. Recombinant truncated GSK was added as substrate and incubated at $37^{\circ} \mathrm{C}$ for $30 \mathrm{~min}$. The reaction was stopped by addition of Laemmeli's sample buffer followed by SDSPAGE and immunoblotting.

\section{DCFH-DA-based ROS assay}

DCFH-DA, an oxidant-sensitive dye that is converted to $2^{\prime}, 7^{\prime}$-dichlorofluorescein (DCF) by oxidation and after deesterification, was employed to measure ROS levels as described elsewhere (1). In brief, synaptosomes were incubated with $10 \mu M$ DCFH-DA in $0.1 M$ phosphate buffer (pH7.4) for 
5 min at room temperature. Fluorescence was measured using excitation at $488 \mathrm{~nm}$ and emission at $525 \mathrm{~nm}$ every $30 \mathrm{~s}$ for $1 \mathrm{~h}$. A standard curve of DCF was always used for quantification of ROS levels in independent experiments (Supplementary Fig. S4).

\section{Primary cortical neuronal cultures}

Primary neuronal cultures were established and maintained as previously described (2). In brief, cortical tissue was dissected out from WT and APP/PS1 P1 mice. The tissue was then enzymatically dissociated using trypsin. The cell suspension obtained after trituration was centrifuged and pellets were resuspended and plated in Neurobasal-A Medium (GIBCO, Life Technologies) containing 1\% 100× Glutamax (GIBCO), $1 \% 100 \times$ penicillin-streptomycin (GIBCO), and $2 \% 50 \times$ B27 (GIBCO).

\section{ROS measurements in primary neurons}

DCFH-DA was used to observe ROS production in primary neurons. Using HEK293T cells, we confirmed the ability of DCF assay to monitor ROS generation in cell culture systems (Supplementary Fig. S5). Primary neurons (DIV 15) grown on coated coverslips were incubated with $10 \mu M$ DCFH-DA for $20 \mathrm{~min}$ at $37^{\circ} \mathrm{C}$, washed with PBS, and fixed using cold acetone for $10 \mathrm{~min}$. The cells were then immunostained for Homer1, mounted on slides, and imaged immediately. Homer1 immunostaining was performed to create a "mask" for image analysis.

\section{Protein translation assay in primary neurons}

Protein translation in primary neurons was assayed as described elsewhere (45). In brief, primary cortical neurons (DIV 15) were stimulated with $50 \mathrm{ng} / \mathrm{ml}$ of BDNF (Life Technologies) for $1 \mathrm{~h}$ at $37^{\circ} \mathrm{C}$, followed by treatment with $3 \mu M$ puromycin (Sigma) for $7 \mathrm{~min}$ at $37^{\circ} \mathrm{C}$. After brief washing, treatment was terminated by fixation with $4 \%(\mathrm{w} / \mathrm{v})$ paraformaldehyde and $4 \%(\mathrm{w} / \mathrm{v})$ sucrose for $20 \mathrm{~min}$ at room temperature. This was followed by permeabilization with $0.3 \%(\mathrm{v} / \mathrm{v})$ Triton X-100. Cells were then coimmunostained with antibodies against MAP2 and puromycin for $1 \mathrm{~h}$ at room temperature.

\section{Overexpression of myristoylated Akt1 in primary neurons}

In some experiments, primary cortical neurons from APP/ PS1 mice were transduced with myristoylated Akt1 (42) lentiviral particles to observe the effects of Akt1 overexpression on BDNF-stimulated protein translation. The pBSFI-myr-akt1 was a gift from Dr. Peter Vogt (Addgene plasmid\# 49186); pMD2.G and psPAX2 were a gift from Dr. Didier Trono (Addgene Plasmid\# 12259, 12260). The pRRLsinPPTeGFP plasmid (pLenti-GFP) was kindly provided by Dr. Philip A. Barker (McGill University, Montreal, QC, Canada). Mouse myr-akt1 open reading frame was amplified by PCR to encode BamHI and SalI restriction sites at the $5^{\prime}$ and $3^{\prime}$ ends, respectively. These products were gel purified and ligated into a pRRLsinPPTeGFP vector to generate pRRLsinPPTmyr-Akt1. Lentiviral particles were produced using second-generation lentiviral systems in HEK293T cells; particles were purified by ultra centrifugation and re- suspended in Neurobasal-A medium, and the amount of active particles was determined by titration in HEK293T cells. Primary cortical neurons from APP/PS1 mice were transduced on DIV13 and experiments were performed on DIV1516. Untransduced cultures from the same batch were used as controls. Akt1 overexpression was confirmed by immunostaining for Akt1.

Images were acquired using Zeiss LSM780 and analyzed using Metamorph software (Molecular Devices LLC).

\section{Statistics}

Outliers from the data set were removed by employing a widely used and accepted statistical method of outlier removal based on median absolute deviation (25). Statistical comparisons were made by using unpaired two-tailed Student's $t$-test. Multiple groups were compared using one-way analyses of variance followed by post hoc tests with Newman-Keuls correction.

\section{Acknowledgments}

We thank Prof. D.N. Rao for help with the $S^{35}$-methionine incorporation assay. This work was supported by grants from Tata Trusts and Departments of Science \& Technology and Biotechnology, India. The study was supported, in part, by NIH grant R01AG17917 (DAB).

\section{Author Disclosure Statement}

The authors declare no conflict of interest.

\section{References}

1. Ahmad F, Nidadavolu P, Durgadoss L, and Ravindranath V. Critical cysteines in Akt1 regulate its activity and proteasomal degradation: implications for neurodegenerative diseases. Free Radic Biol Med 74: 118-128, 2014.

2. Beaudoin GM, 3rd, Lee SH, Singh D, Yuan Y, Ng YG, Reichardt LF, and Arikkath J. Culturing pyramidal neurons from the early postnatal mouse hippocampus and cortex. Nat Protoc 7: 1741-1754, 2012.

2a. Bennett DA, Schneider JA, Buchman AS, Barnes LL, Boyle PA, and Wilson RS. Overview and findings from the Rush Memory and Aging Project. Curr Alzheimer Res 9: 646-663, 2014.

3. Bermejo MK, Milenkovic M, Salahpour A, and Ramsey AJ. Preparation of synaptic plasma membrane and postsynaptic density proteins using a discontinuous sucrose gradient. J Vis Exp 91: e51896, 2014.

4. Borchelt DR, Ratovitski T, van Lare J, Lee MK, Gonzales V, Jenkins NA, Copeland NG, Price DL, and Sisodia SS. Accelerated amyloid deposition in the brains of transgenic mice coexpressing mutant presenilin 1 and amyloid precursor proteins. Neuron 19: 939-945, 1997.

5. Bramham CR, Alme MN, Bittins M, Kuipers SD, Nair RR, Pai B, Panja D, Schubert M, Soule J, Tiron A, and Wibrand K. The Arc of synaptic memory. Exp Brain Res 200: 125-140, 2010.

6. Buffington SA, Huang W, and Costa-Mattioli M. Translational control in synaptic plasticity and cognitive dysfunction. Аnпu Rev Neurosci 37: 17-38, 2014.

7. Butterfield DA, Di Domenico F, and Barone E. Elevated risk of type 2 diabetes for development of Alzheimer disease: a key role for oxidative stress in brain. Biochim Biophys Acta 1842: 1693-1706, 2014. 
8. This reference has been deleted.

9. Damjanac M, Rioux Bilan A, Paccalin M, Pontcharraud R, Fauconneau B, Hugon J, and Page G. Dissociation of Akt/ $\mathrm{PKB}$ and ribosomal S6 kinase signaling markers in a transgenic mouse model of Alzheimer's disease. Neurobiol Dis 29: 354-367, 2008.

10. Di Liegro CM, Schiera G, and Di Liegro I. Regulation of mRNA transport, localization and translation in the nervous system of mammals (Review). Int J Mol Med 33: 747-762, 2014.

11. Durgadoss L, Nidadavolu P, Valli RK, Saeed U, Mishra M, Seth $\mathrm{P}$, and Ravindranath V. Redox modification of Akt mediated by the dopaminergic neurotoxin MPTP, in mouse midbrain, leads to down-regulation of pAkt. FASEB J 26: 1473-1483, 2012.

12. Ebert DH, and Greenberg ME. Activity-dependent neuronal signalling and autism spectrum disorder. Nature 493: 327337, 2013.

13. Flynn A, and Proud CG. The role of eIF4 in cell proliferation. Cancer Surv 27: 293-310, 1996.

14. Gal-Ben-Ari S, Kenney JW, Ounalla-Saad H, Taha E, David O, Levitan D, Gildish I, Panja D, Pai B, Wibrand K, Simpson TI, Proud CG, Bramham CR, Armstrong JD, and Rosenblum K. Consolidation and translation regulation. Learn Mem 19: 410-422, 2012.

15. Gong R, Park CS, Abbassi NR, and Tang SJ. Roles of glutamate receptors and the mammalian target of rapamycin (mTOR) signaling pathway in activity-dependent dendritic protein synthesis in hippocampal neurons. $J$ Biol Chem 281: 18802-18815, 2006.

16. Griffin RJ, Moloney A, Kelliher M, Johnston JA, Ravid R, Dockery P, O'Connor R, and O'Neill C. Activation of Akt/ $\mathrm{PKB}$, increased phosphorylation of Akt substrates and loss and altered distribution of Akt and PTEN are features of Alzheimer's disease pathology. J Neurochem 93: 105-117, 2005.

17. Heise C, Gardoni F, Culotta L, di Luca M, Verpelli C, and Sala C. Elongation factor-2 phosphorylation in dendrites and the regulation of dendritic mRNA translation in neurons. Front Cell Neurosci 8: 35, 2014.

18. Hers I, Vincent EE, and Tavare JM. Akt signalling in health and disease. Cell Signal 23: 1515-1527, 2011.

19. Hoeffer CA and Klann E. mTOR signaling: at the crossroads of plasticity, memory and disease. Trends Neurosci 33: 67-75, 2010.

20. Jack CR, Jr., Knopman DS, Jagust WJ, Shaw LM, Aisen PS, Weiner MW, Petersen RC, and Trojanowski JQ. Hypothetical model of dynamic biomarkers of the Alzheimer's pathological cascade. Lancet Neurol 9: 119-128, 2010.

21. Kindler S and Kreienkamp HJ. Dendritic mRNA targeting and translation. Adv Exp Med Biol 970: 285-305, 2012.

22. Kumar V, Zhang MX, Swank MW, Kunz J, and Wu GY. Regulation of dendritic morphogenesis by Ras-PI3K-AktmTOR and Ras-MAPK signaling pathways. J Neurosci 25: 11288-11299, 2005.

23. Lafay-Chebassier C, Paccalin M, Page G, Barc-Pain S, Perault-Pochat MC, Gil R, Pradier L, and Hugon J. mTOR/ p70S6k signalling alteration by Abeta exposure as well as in APP-PS1 transgenic models and in patients with Alzheimer's disease. J Neurochem 94: 215-225, 2005.

24. Lee TL, Raygada MJ, and Rennert OM. Integrative gene network analysis provides novel regulatory relationships, genetic contributions and susceptible targets in autism spectrum disorders. Gene 496: 88-96, 2012.

25. Leys C, Ley C, Klein O, and Bernard P, Licata L. Detecting outliers: do not use standard deviation around the mean, use absolute deviation around the median. J Exp Soc Psychol 49: 764-766, 2013.

26. Liao FF and $\mathrm{Xu} \mathrm{H}$. Insulin signaling in sporadic Alzheimer's disease. Sci Signal 2: pe36, 2009.

27. Liu Y, Liu F, Grundke-Iqbal I, Iqbal K, and Gong CX. Deficient brain insulin signalling pathway in Alzheimer's disease and diabetes. J Pathol 225: 54-62, 2011.

28. Ma T and Klann E. Amyloid beta: linking synaptic plasticity failure to memory disruption in Alzheimer's disease. J Neurochem 120 Suppl 1: 140-148, 2012.

29. Ma T, Trinh MA, Wexler AJ, Bourbon C, Gatti E, Pierre P, Cavener DR, and Klann E. Suppression of eIF2alpha kinases alleviates Alzheimer's disease-related plasticity and memory deficits. Nat Neurosci 16: 1299-1305, 2013.

30. Mamane Y, Petroulakis E, LeBacquer O, and Sonenberg N. mTOR, translation initiation and cancer. Oncogene 25: 6416-6422, 2006.

31. Meraz-Rios MA, Franco-Bocanegra D, Toral Rios D, and Campos-Pena V. Early onset Alzheimer's disease and oxidative stress. Oxid Med Cell Longev 2014: 375968, 2014.

32. Muddashetty RS, Kelic S, Gross C, Xu M, and Bassell GJ. Dysregulated metabotropic glutamate receptor-dependent translation of AMPA receptor and postsynaptic density-95 mRNAs at synapses in a mouse model of fragile $\mathrm{X}$ syndrome. J Neurosci 27: 5338-5348, 2007.

33. Nakagami Y. Inhibitors beta-amyloid-induced toxicity by modulating the Akt signaling pathway. Drug News Perspect 17: 655-660, 2004.

34. Nave BT, Ouwens M, Withers DJ, Alessi DR, and Shepherd PR. Mammalian target of rapamycin is a direct target for protein kinase B: identification of a convergence point for opposing effects of insulin and amino-acid deficiency on protein translation. Biochem J 344 Pt 2: 427-431, 1999.

34a. O' Neill C. PI3-kinase/Akt/mTOR signaling: impaired on/ off switches in aging, cognitive decline and Alzheimer's disease. Exp Gerontol 48: 647-653, 2013.

35. Overk CR, and Masliah E. Pathogenesis of synaptic degeneration in Alzheimer's disease and Lewy body disease. Biochem Pharmacol 88: 508-516, 2014.

36. Richter JD, and Klann E. Making synaptic plasticity and memory last: mechanisms of translational regulation. Genes Dev 23: 1-11, 2009.

37. Ryder J, Su Y, and Ni B. Akt/GSK3beta serine/threonine kinases: evidence for a signalling pathway mediated by familial Alzheimer's disease mutations. Cell Signal 16: 187200, 2004.

38. Sancheti H, Akopian G, Yin F, Brinton RD, Walsh JP, and Cadenas E. Age-dependent modulation of synaptic plasticity and insulin mimetic effect of lipoic acid on a mouse model of Alzheimer's disease. PLoS One 8: e69830, 2013.

39. Santini E, Huynh TN, and Klann E. Mechanisms of translation control underlying long-lasting synaptic plasticity and the consolidation of long-term memory. Prog Mol Biol Transl Sci 122: 131-167, 2014.

40. Schagger H. Tricine-SDS-PAGE. Nat Protoc 1: 16-22, 2006.

41. Sehgal N, Gupta A, Valli RK, Joshi SD, Mills JT, Hamel E, Khanna P, Jain SC, Thakur SS, and Ravindranath V. Withania somnifera reverses Alzheimer's disease pathology by enhancing low-density lipoprotein receptor-related protein in liver. Proc Natl Acad Sci U S A 109: 3510-3515, 2012.

42. Shin I, Yakes FM, Rojo F, Shin NY, Bakin AV, Baselga J, and Arteaga CL. PKB/Akt mediates cell-cycle progression 
by phosphorylation of p27(Kip1) at threonine 157 and modulation of its cellular localization. Nat Med 8: 11451152, 2002.

43. Suwanna N, Thangnipon W, and Soi-Ampornkul R. Neuroprotective effects of diarylpropionitrile against betaamyloid peptide-induced neurotoxicity in rat cultured cortical neurons. Neurosci Lett 578: 44-49, 2014.

44. Takei N, Inamura N, Kawamura M, Namba H, Hara K, Yonezawa K, and Nawa $\mathrm{H}$. Brain-derived neurotrophic factor induces mammalian target of rapamycin-dependent local activation of translation machinery and protein synthesis in neuronal dendrites. J Neurosci 24: 9760-9769, 2004.

45. tom Dieck S, Kochen L, Hanus C, Heumuller M, Bartnik I, Nassim-Assir B, Merk K, Mosler T, Garg S, Bunse S, Tirrell DA, and Schuman EM. Direct visualization of newly synthesized target proteins in situ. Nat Methods 12: 411-414, 2015.

46. Tramutola A, Triplett JC, Di Domenico F, Niedowicz DM, Murphy MP, Coccia R, Perluigi M, and Butterfield DA. Alteration of mTOR signaling occurs early in the progression of Alzheimer disease (AD): analysis of brain from subjects with pre-clinical $\mathrm{AD}$, amnestic mild cognitive impairment and late-stage AD. J Neurochem 133: 739-749, 2015.

47. Troca-Marin JA, Alves-Sampaio A, and Montesinos ML. Deregulated mTOR-mediated translation in intellectual disability. Prog Neurobiol 96: 268-282, 2012.

48. Wang DO, Martin KC, and Zukin RS. Spatially restricting gene expression by local translation at synapses. Trends Neurosci 33: 173-182, 2010.

49. Williams C, Mehrian Shai R, Wu Y, Hsu YH, Sitzer T, Spann B, McCleary C, Mo Y, and Miller CA. Transcriptome analysis of synaptoneurosomes identifies neuroplasticity genes overexpressed in incipient Alzheimer's disease. PLoS One 4: e4936, 2009.

Address correspondence to: Prof. Vijayalakshmi Ravindranath Centre for Neuroscience

Indian Institute of Science

C.V. Raman Avenue

Bangalore 560012

India

E-mail: viji@cns.iisc.ernet.in

Date of first submission to ARS Central, August 11, 2016; date of final revised submission, February 27, 2017; date of acceptance, February 27, 2017.

\section{Abbreviations Used}

4EBP1 = eukaryotic translation initiation factor 4E-binding protein 1

$\mathrm{AD}=$ Alzheimer's disease
$\mathrm{ADL}=$ adolescent

Akt1 $=$ RAC-alpha serine/threonine-protein kinase

AMS $=4$-acetamido-4' -maleimidylstilbene-2,2' disulfonic acid, disodium salt

APP/PS1 = amyloid precursor protein/presenilin 1 double mutant

Arc $=$ activity regulated cytoskeleton-associated protein

ATCC $=$ American Type Culture Collection

$\mathrm{A} \beta=$ amyloid beta

$\mathrm{BDNF}=$ brain-derived neurotrophic factor

$\mathrm{CHX}=$ cycloheximide

$\mathrm{DCF}=2^{\prime}, 7^{\prime}$-dichlorodihydrofluorescein

DCFH-DA $=2^{\prime}, 7^{\prime}$-dichlorodihydrofluorescein diacetate DTT $=1,4$-dithiothreitol

eIF4E $=$ eukaryotic translation initiation factor $4 \mathrm{E}$

$\mathrm{GSH}=$ glutathione

$\mathrm{GSK}=$ glycogen synthase kinase

$\mathrm{HRP}=$ horse-radish peroxidase

$\mathrm{KCl}=$ potassium chloride

$\mathrm{MA}=$ middle aged

MAP2 $=$ microtubule-associated protein 2

MCI $=$ mild cognitive impairment

MRI = magnetic resonance imaging

$\mathrm{mRNA}=$ messenger ribonucleic acid

$\mathrm{mTOR}=$ mechanistic target of rapamycin

Myr-Akt1 $=$ myristoylated Akt1

$\mathrm{NaOH}=$ sodium hydroxide

$\mathrm{NCI}=$ no cognitive impairment

$\mathrm{ORF}=$ open reading frame

p4EBP1 = phosphorylated 4EBP1

pAkt1 $=$ phosphorylated Akt1

$\mathrm{PET}=$ positron emission tomography

$\mathrm{PKB}=$ protein kinase $\mathrm{B}$

pmTOR $=$ phosphorylated $\mathrm{mTOR}$

$\mathrm{PNS}=$ postnuclear supernatant

$\mathrm{PP} 2 \mathrm{~A}=$ protein phosphatase $2 \mathrm{~A}$

pS6K $=$ phosphorylated S6K

PSD95 $=$ postsynaptic density protein 95

ROS $=$ reactive oxygen species

$\mathrm{S}^{35}=$ sulfur 35

$\mathrm{S} 6=$ ribosomal protein S6

$\mathrm{S} 6 \mathrm{~K}=$ ribosomal protein S6 kinase beta-1

$\mathrm{SD}=$ standard deviation

SDS-PAGE $=$ sodium dodecyl sulfate polyacrylamide gel electrophoresis

$\mathrm{SEM}=$ standard error of mean

Ser $=$ serine

SNAP29 = synaptosome-associated protein $29 \mathrm{kDa}$

$\mathrm{TCA}=$ trichloroacetic acid

$\mathrm{Thr}=$ threonine

$\mathrm{TMB}=3,3^{\prime}, 5,5^{\prime}$-tetramethylbenzidine

TSC $1 / 2=$ tuberous sclerosis protein complex $1 / 2$

$\mathrm{WT}=$ wild type

$\mathrm{YA}=$ young adult 